\title{
Estimation of gas hydrate saturation using isotropic and anisotropic modelling in the Mahanadi basin
}

\author{
Uma Shankar* and Ashok Kumar Pandey \\ Department of Geophysics, Institute of Science, Banaras Hindu University, Varanasi 221 005, India. \\ *Corresponding author.e-mail: umashankar@bhu.ac.in
}

MS received 5 March 2018; revised 1 February 2019; accepted 26 February 2019; published online 13 June 2019

A base of gas hydrate stability zone was established after coring and drilling under the National Gas Hydrate Program (NGHP) Expedition-01 in the Mahanadi basin. At two sites, logging-while-drilling log data, and, at one site, wireline log data, were acquired during the NGHP Expedition-01. Gas hydrate reservoirs modelling can be performed in two different ways. One way is isotropic (load bearing) and, on the other hand, anisotropic media (fracture filling with gas hydrate). Here, we have performed anisotropic modelling and estimated gas hydrate saturation using P-wave velocity, assuming an incidence angle of $75^{\circ}$ represents the vertical fracture. The estimated gas hydrate saturation at sites NGHP-01-08 and NGHP01-09, assuming anisotropic media, reduces the estimate by half compared to the saturation estimation by assuming isotropic media. The saturation at site NGHP-01-19 estimated from the isotropic and anisotropic P-wave velocity models are more or less similar except in the zone $(175-210 \mathrm{~m})$ just above the bottom simulating reflector depth, and this zone shows similar reduction in saturation as estimated at sites NGHP-01-08 and NGHP-01-09. Observations show that average gas hydrate saturations are relatively low (up to $5 \%$ of the pore space). The saturation of a gas hydrate estimated from an isotropic $\mathrm{P}$-wave model varies from $5 \%$ to $20 \%$. However, the saturation estimated from the anisotropic P-wave model shows a variation up to $10 \%$ of the pore spaces at three sites.

Keywords. Gas hydrate; Mahanadi basin; well logs; rock physics modelling; saturation; anisotropy.

\section{Introduction}

A gas hydrate is an ice-like crystalline solid substance, in which gas molecules (mainly methane) are trapped by water molecules and consist of water and low hydrocarbon molecules (mainly methane). Gas hydrates have been identified in the Mahanadi basin from the analysis of highresolution multi-channel seismic data (Mathur et al. 2008; Ramana et al. 2009; Bastia et al. 2010a, b; Prakash et al. 2010; Sain et al. 2012) and established by drilling and coring (Collett et al. 2008). The bottom simulating reflectors (BSRs), prime marker for gas hydrates, have been observed at the seismic section in the Mahanadi basin. A high reflection strength and low seismic velocity below BSRs characterising free gas-bearing sediments were also observed in the central part of the basin (Collett et al. 2008; Shankar and Riedel 2014). Additional three-dimensional (3D) seismic data were analysed for BSRs and seismic proxies related to the presence of the natural gas hydrate in the Mahanadi basin (Mathur et al. 2008; Prakash et al. 2010; Shankar and Riedel 2014). This analysis shows the presence of BSRs and BSR-like features over a large area 
of nearly $250 \mathrm{~km}^{2}$ in the central western part of the basin.

The formation of the gas hydrate in marine sediments usually changes the physical properties of the bulk sediment and creates anisotropy subsequently. In marine sediments, gas hydrates occur in various morphologies such as pore filling, fracture filling, small nodules, lenses and veins. In the simplest model, rising methane combines with the sediment pore fluid to form a gas hydrate, partially replacing the pore fluid with little change to the sediment structure or volume. More complex models involve gas hydrate crystal growth by the displacement of the ambient sediment, in the case of veins, fracture fill, small nodules or lenses. The presence of gas hydrates in pore spaces of marine sediments can therefore significantly affect the bulk physical properties of the sediments. The gas hydrate-bearing sediments exhibit relatively higher seismic velocity than that of the background (without gas hydrates) velocity. Seismic velocities are related to the saturation of gas hydrates, mostly through the empirical porosity-velocity relationship based on effective porosity reduction models (Yuan et al. 1996), time-averaging approaches (Lee et al. 1993) and first-principles-based rock-physics modelling approaches (Dvorkin and Nur 1993; Helgerud et al. 1999; Carcione and Tinivella 2000).

Velocity appears to be the most strongly affected by the presence of gas hydrates in marine sediments. Gas hydrate inclusion in the pore space of marine sediments can significantly affect the bulk physical properties of the sediment. The measurement of such properties can therefore be used to estimate gas hydrate saturation (Yuan et al. 1996;
Collett and Ladd 2000). Down-hole P-wave sonic logs have been used extensively to characterise the in situ properties of gas hydrate-bearing sediments and the estimation of gas hydrate saturations (Guerin et al. 1999; Helgerud et al. 1999; Hyndman et al. 1999, 2001; Collett 2002; Lee and Collett 2005; Lee and Waite 2008; Ojha and Sain 2013; Shankar et al. 2013; Satyavani et al. 2015). In this study, gas hydrate saturation estimates are described using isotropic and anisotropic $\mathrm{P}$-wave velocity analyses and an effective medium modelling approach to predict the $\mathrm{P}$-wave velocity for different amounts of gas hydrate saturation in the sediments.

An incidence angle of $0^{\circ}$ represents a horizontal fracture and an incidence angle of $90^{\circ}$ represents a vertical fracture (Lee and Collett 2009). When the $\mathrm{P}$ - and $\mathrm{S}$-wave velocities were measured, the gas hydrate saturation and fracture angles can be calculated using White's (1965) equation. The $\mathrm{P}$-wave velocity is used to calculate gas hydrate saturations using a model of elastic velocities in laminated media assuming a fracture dip angle (Lee and Collett 2009; Wang et al. 2013).

Here, we use three sites in the Mahanadi basin from the NGHP Expedition-01. The sites NGHP01-08 and NGHP-01-09 are situated at greater water depths of $\sim 1689$ and $\sim 1935 \mathrm{~m}$, respectively. The site NGHP-01-19 is located at a shallower water depth of $\sim 1422 \mathrm{~m}$ in the central part of the basin (figure 1). We assume that the gas hydrate primarily replaces a portion of the sediment pore fluid, since no massive gas hydrates were recovered at these sites and dispersed gas hydrates have been inferred from the analysis of the available data (Collett et al. 2008; Shankar and Riedel 2014).
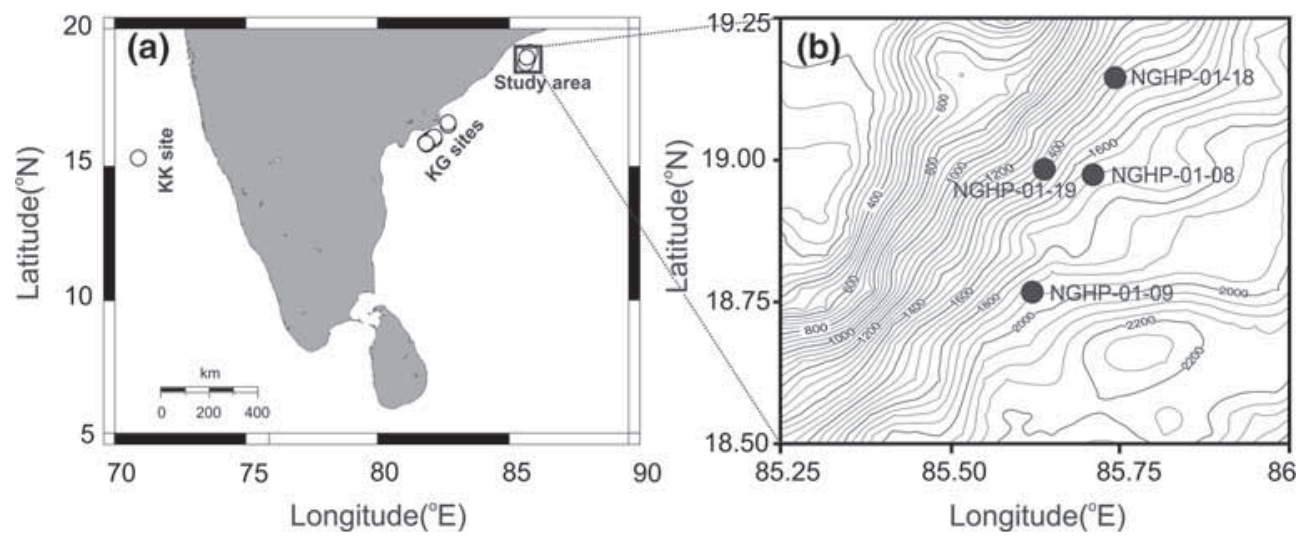

Figure 1. (a) Study area in the Mahanadi basin on the eastern margin of India. (b) Details of the bathymetry of the basin with the location of drilling sites shown with black dots. 


\section{Geological setting}

The Mahanadi basin was formed during the rifting and break-up of the Gondwanaland during the Jurassic period. The tectonics of the Mahanadi basin represents a rift zone trending to the NESW direction. The rift zone lies to the SE of the outcropping NW-SE-trending Gondwana Permian Triassic Mahanadi rift zone (Fuloria et al. 1992; Subrahmanyam et al. 2008). Its structural setting contains the NE-SW-striking JurassicLower Cretaceous fault pattern that controls a system of depressions and highs. Significant volcanic activity is observed in both the PermianTriassic and the Jurassic-Lower Cretaceous rift zones (Fuloria et al. 1992).

The areal extent of the basin is about $260,000 \mathrm{~km}^{2}$ including the deep waters (Mohapatra 2006). The Mahanadi offshore basin covers an area of $\sim 80,000 \mathrm{~km}^{2}$ in the Bay of Bengal, south of the Bengal shelf with a water depth ranging from $\sim 100$ to $\sim 2500 \mathrm{~m}$ (Dangwal et al. 2008). The sediment thickness in the Mahanadi deep water basin is more than $8 \mathrm{~km}$ of Upper Cretaceous to Recent age. The bulk of these sediments was supplied from the Ganga-Brahmaputra deltaic system during the Mio-Pliocene times. During the Early Palaeogene, the basin experienced passive margin carbonate and finer clastic sedimentation, while during the Neogene, it received major fan sediments from the system (Bharali et al. 1991). The Mahanadi basin has a favourable temperature and pressure conditions required for the formation of gas hydrates. The basin is characterised by geothermal gradients of $35-45^{\circ} \mathrm{C} / \mathrm{km}$ and a high sedimentation rate. The overall sediment flux that is received in this basin is mainly from the Mahanadi river system (Mahanadi, Brahmani, Baitarani and Dhamara rivers) with a sediment load to the basin on the order of $7.10 \times 10^{9} \mathrm{~kg} / \mathrm{yr}$ (Subramanian 1978). The total organic carbon content is estimated to be more than 1.5\% (Collett et al. 2008) that favours the formation of gas hydrates in this region.

\section{Materials and method}

\subsection{Sonic log data}

Figure 2 shows the suite of logs recorded at site NGHP-01-19 in the Mahanadi basin. The vertical resolution of the tool is $107 \mathrm{~cm}$, and the depth of the investigation is $\sim 10 \mathrm{~cm}$ (Shankar and Riedel 2011). The hole size calculated from the calliper $\log$ shows an irregular hole, with alternating washouts and ledges where the hole can be smaller than the bit size. Despite the irregular size, the quality of the data should be only moderately affected. An indication of the general good data quality is in close correspondence to the density log and the core measurements (Shankar and Riedel 2014). While this naturally coincides with a good agreement between the porosity measurements on core samples and the density derived porosity log, the neutron porosity log, however, indicates larger
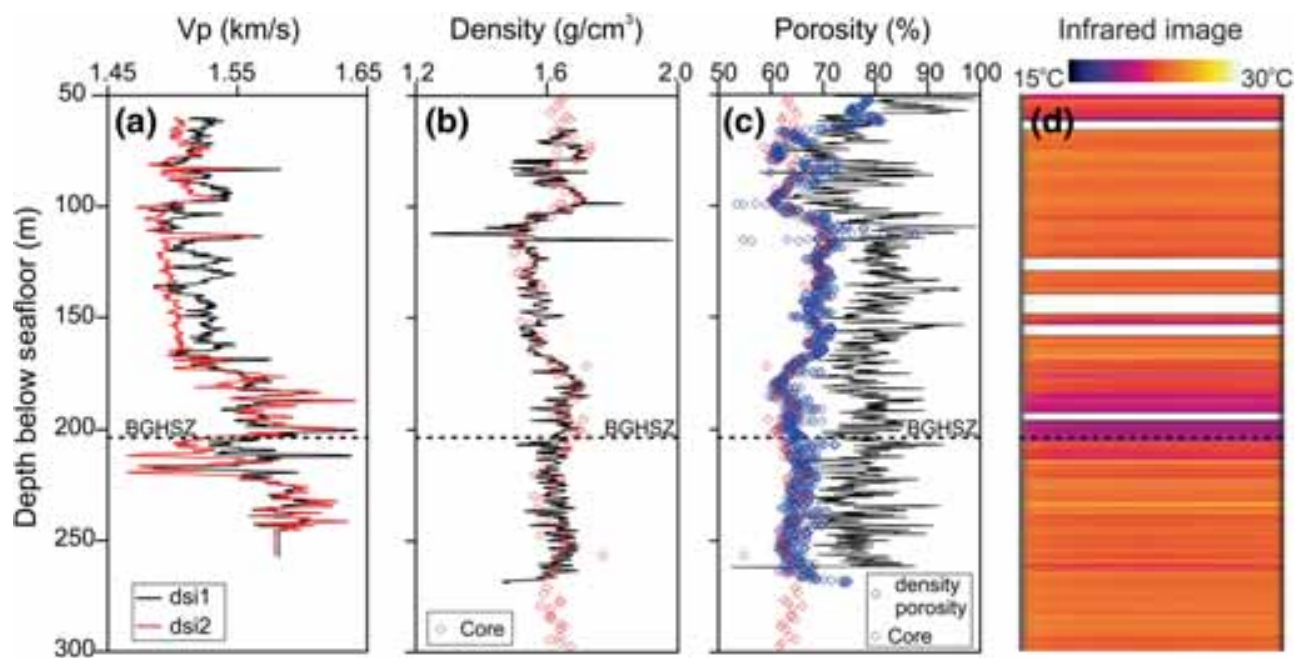

Figure 2. Suite of logs from site NGHP-01-19, and the BGHSZ is highlighted by the dashed black line, (a) sonic P-wave velocity with two runs shown in two colours, (b) measured bulk density (RHOB) (black curve), red diamond shows measured core samples density, (c) neutron porosity (black curve), porosity values (red diamond) measured from core samples and blue diamonds are porosity values derived from the density log and (d) IR images along the recovered cores. 
values due to the bound clay water. This difference is due to the large hole at some intervals, but it is mainly related to the large amount of clay in this formation, which is not corrected for in the neutron porosity log. The quality of the sonic log is highly dependent on borehole conditions, and requires good contact between the tool and the borehole wall.

The P-wave velocities for site NGHP-01-19 from the NGHP Expedition-01 from the Mahanadi basin are shown in figure 2(a). Two runs of the DSI tool (dsi1 and dsi2) are shown with different colours (figure 2a). The sonic velocity log shows an increasing trend of $\mathrm{P}$-wave velocity values with a depth and maximum velocity values are observed just above the BSR at $\sim 205$ mbsf within the gas hydrate stability zone (GHSZ) (figure 2a). A sudden drop in the $\mathrm{P}$-wave velocity to $\sim 1.53 \mathrm{~km} / \mathrm{s}$ is observed just below the base of GHSZ (BGHSZ) and the velocity again increases up to $1.63 \mathrm{~km} / \mathrm{s}$ (figure 2a). However, no visible gas hydrate samples were recovered from this site. The infrared (IR) camera identified a steady decrease in temperature with depth measured on the core liner above 205 mbsf, which was interpreted as the indication of the gas hydrate disseminated in the formation above BGHSZ (figure 2d). The density and porosity measurements of core samples are superimposed on the corresponding logs. The density log matches reasonably with the measured core despite the irregular hole size. The density porosity, calculated from the density log that shows good correspondence with the porosity measured from the core samples, is a direct indicator of the precise measurement of density log data (figure 2c). The neutron porosity log shows consistently higher than the measured core porosity because of the influence of mineral-bound water in these clay-dominated sediments (Collett et al. 2008) (figure 2c). The shallow zone of the log above 60 mbsf cannot be used as the calliper log shows a much enlarged hole near the seafloor. Coring is not performed at sites NGHP-01-08 and NGHP-01-09 and only loggingwhile-drilling (LWD) logs were acquired at these two sites.

\subsection{Rock physics modelling}

Rock physics models are used to estimate the geo-mechanical properties such as the elastic moduli from the porosity and mineralogical constituents of the sediment matrix. Several rock physics models are developed to predict the elastic moduli of shallow unconsolidated marine sediments as a function of porosity, mineralogy, effective pressure and pore-fluid compressibility. Each of these theories has its own sets of assumptions and application of some site-specific empirical relations. Pore-filling models usually approximate the rock as a nonelastic solid containing pore spaces. The presence of pore space is more compliant than solid mineral, as it has the effect of reducing the overall elastic stiffness of the rock in either an isotropic or anisotropic way. The vast majority of pore-filling models assume that the pore cavities are spherical (Kuster and Toksöz 1974; Dai et al. 2008; Holland et al. 2008). Contact models approximate the rock as a combination of different grains, whose elastic properties are determined by the deformability and stiffness of their grain-to-grain contacts (Ecker et al. 1998, 2000; Dvorkin et al. 1999, 2003; Helgerud et al. 1999; Jakobsen et al. 2000; Dai et al. 2004; Xu et al. 2004). Dvorkin and Nur (1996) described the effect of adding small amounts of mineral cement at the contacts of spherical grains.

Transformations include models such as the Gassmann (1951) relations for fluid substitution, which are relatively free of geometric assumptions. The Gassmann relations take measured $V_{\mathrm{p}}$ and $V_{\mathrm{s}}$ at one fluid state and predict the $V_{\mathrm{p}}$ and $V_{\mathrm{s}}$ of another fluid state (Berryman and Milton 1991). The geometry-independent scheme to predict fluid substitution in a composite of two moduli of different sediment types of two different places (Cook et al. 2008; Holland et al. 2008; Kastner et al. 2008; Ghosh et al. 2010). Mavko et al. (1995) derived a geometry-independent transformation to take velocity versus pressure data and predict stress-induced anisotropy. Mavko and Jizba (1991) presented a transformation of measured dry velocity versus pressure to predict velocity frequency in fluid-saturated rocks. The most common approach to modelling the stress-induced anisotropy is to assume the angular distributions of idealised penny-shaped cracks (Nur 1971; Gibson and Toksoz 1990). The stress dependence is introduced by assuming or inferring distributions or spectra of crack aspect ratios with various orientations. The procedure is to estimate the generalised pore-space compliance from the measurements of isotropic $V_{\mathrm{p}}$ and $V_{\mathrm{s}}$.

\subsubsection{Isotropic medium}

Helegrud's (1999) model considers the effect of the gas hydrate on the sediment's elastic moduli. The model requires porosity and the elastic moduli of 
the sediment grains, pore water and free gas. In our modelling, we considered hydrate as a component of the solid phase, modifying the elasticity of the frame. Background velocity is estimated using the method of Dvorkin et al. (1999), which expresses the bulk and shear moduli of dry marine sediments. Effective saturated bulk modulus of the sediment is calculated from the following relation given by Dvorkin and Nur (1998):

$$
\begin{aligned}
& K_{\mathrm{Sat}}=\left[\frac{S_{\mathrm{W}}}{K_{\mathrm{SatW}}+(4 / 3) G_{\mathrm{dry}}}\right. \\
&\left.+\frac{1-S_{\mathrm{W}}}{K_{\mathrm{SatG}}+(4 / 3) G_{\mathrm{dry}}}\right]^{-1}-\frac{4}{3} G_{\mathrm{dry}},
\end{aligned}
$$

where $K_{\text {SatW }}$ and $K_{\text {SatG }}$ are the bulk moduli of the sediment fully saturated with water and gas, respectively, and $S_{\mathrm{w}}$ is water saturation. They are calculated using Gassmann's (1951) equation. Once the elastic parameters are known, the elastic velocities, $V_{\mathrm{p}}$ and $V_{\mathrm{s}}$, can be calculated as

$$
\begin{aligned}
& V_{\mathrm{p}}=\frac{K_{\text {Sat }}+(4 / 3) G_{\text {Sat }}}{\rho_{\mathrm{b}}}, \\
& V_{\mathrm{s}}=\frac{G_{\text {Sat }}}{\rho_{\mathrm{b}}},
\end{aligned}
$$

where $V_{\mathrm{p}}$ and $V_{\mathrm{s}}$ are the background velocity and $\rho_{\mathrm{b}}$ is the sediment bulk density.

Elastic anisotropy can be observed due to the aligned cracks in the porous rock in marine sediments. Depending on the phase angle, the isotropic velocities are smaller or larger than anisotropic velocities (Lee and Collett 2009). The P-wave velocity has only a small amount of anisotropy compared to the $\mathrm{S}$-wave velocity. For the $\mathrm{P}$-wave velocity, the phase and group velocities are similar. A sedimentary unit composed of two components is considered where the first component has a $\mathrm{P}$-wave velocity $\left(V_{\mathrm{P}}^{1}\right)$ and density $\left(\rho_{1}\right)$, and the second component is characterised by a $\mathrm{P}$-wave velocity $\left(V_{\mathrm{P}}^{2}\right)$ and density $\left(\rho_{2}\right)$. The phase velocities of transverse isotropic media caused from anisotropy can be computed using the following equation (White 1965):

$$
\begin{gathered}
A=\left\{\frac{4 \mu(\lambda+\mu)}{(\lambda+2 \mu)}\right\}+\left(\frac{1}{(\lambda+2 \mu)}\right)^{-1}\left(\frac{\lambda}{(\lambda+2 \mu)}\right)^{2} \\
C=\left(\frac{1}{(\lambda+2 \mu)}\right)^{-1} \\
F=\left(\frac{1}{(\lambda+2 \mu)}\right)^{-1}\left(\frac{\lambda}{(\lambda+2 \mu)}\right) \\
L=\left(\frac{1}{(\mu)}\right)^{-1}
\end{gathered}
$$

A variation of the obtained velocity from the background velocity provides estimates of saturation at each depth point. The velocity values are iterated in the background until measured and estimated velocity shows close correspondence. Thereby, saturation can be estimated at each depth point.

\subsubsection{Anisotropic medium}

A wide range of potential problems, involving the anisotropic medium can be transformed into equivalent problems involving only an isotropic medium. Here, we consider anisotropy due to the fracture-filled gas hydrate. Marine sediments are commonly having anisotropic seismic properties.

\section{Results and discussion}

Elastic properties of effective media containing various amounts of gas hydrate or free gas can then be calculated according to different assumptions concerning their formation mechanisms (Helgerud 
Table 1. Elastic properties of sediment constituents (after Helgerud 2001).

\begin{tabular}{|c|c|c|c|c|c|}
\hline $\begin{array}{l}\text { Sediment } \\
\text { constituents }\end{array}$ & $\begin{array}{l}\text { Bulk modulus } \\
\qquad(\mathrm{GPa})\end{array}$ & $\begin{array}{l}\text { Shear modulus } \\
\qquad(\mathrm{GPa})\end{array}$ & $\begin{array}{l}\text { Density } \\
\left(\mathrm{g} / \mathrm{cm}^{3}\right)\end{array}$ & $\begin{array}{c}\text { P-wave velocity } \\
(\mathrm{km} / \mathrm{s})\end{array}$ & $\begin{array}{l}\text { S-wave velocity } \\
(\mathrm{km} / \mathrm{s})\end{array}$ \\
\hline Clay & 20.9 & 6.85 & 2.58 & 3.41 & 1.63 \\
\hline Quartz & 36.6 & 45.0 & 2.65 & 6.04 & 4.12 \\
\hline Pore water & 2.4 & 0.0 & 1.03 & 1.5 & 0.0 \\
\hline Methane hydrate & 8.7 & 3.5 & 0.92 & 3.8 & 2.0 \\
\hline Methane gas & 0.1245 & 0.0 & 0.25 & 0.71 & 0.0 \\
\hline
\end{tabular}

et al. 1999). Gas hydrate is modelled either as part of the pore fluid (gas hydrate in-pore), or as part of the load-bearing sediment matrix (gas hydrate in-frame). The gas hydrate in-pore model assumes that the gas hydrate occurs in the sediment pore space, without adding stiffness to the sediment frame. As a consequence, the sediment S-(shear) wave velocity is nearly unaffected by the occurrence of the gas hydrate. For the gas hydrate in-frame model, the elastic properties of the sediment frame are recalculated, with grains of gas hydrate included as part of the sediment frame. Under this mode of occurrence, the gas hydrate adds some stiffness to the sediment frame, and the sediment S-wave velocity is slightly increased by the gas hydrate but much less than for a model in which the gas hydrate cements the grain contacts (Dvorkin and Nur 1993). Both the gas hydrate in-pore and in-frame models predict an increase in $\mathrm{P}$-wave velocity with increased gas hydrate saturation (slightly more for the gas hydrate inframe model).

A reference velocity-depth profile is calculated from the Helgerud (2001) rock-physics model to match the observations in the measured LWD/wireline velocity logs at each well site. Neutron porosity was measured for two sites NGHP-01-08 and NGHP-01-09 and the porosity was derived from the density used for site NGHP-01-19 in our calculation. Two porosity trends are adopted: one is the smoothed linear fit, and the other, a $3-\mathrm{m}$ running average porosity-depth profile. The averaging mineralogy is taken to be $90 \%$ clay and $10 \%$ quartz, with the elastic parameters of the sediment constituents summarised in table 1 . To estimate gas hydrate saturation, $\mathrm{P}$-wave velocity versus depth profiles for various gas hydrate saturations are computed, using the gas hydrate in-frame model. These constant gas hydrate saturation profiles are plotted with the measured P-wave velocity data to provide an estimate of the gas hydrate saturation.

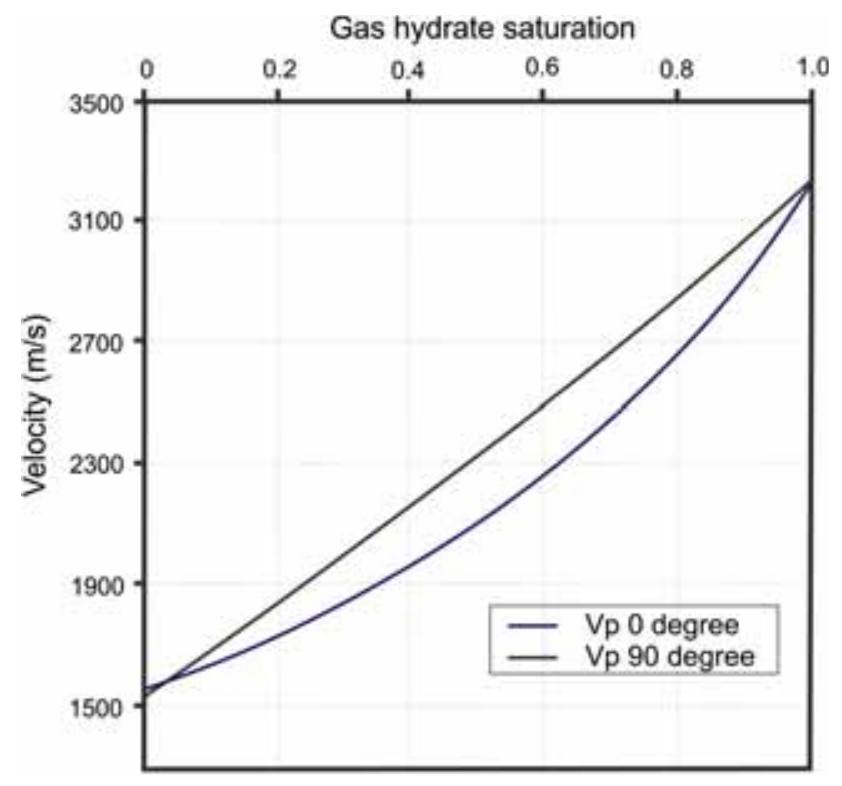

Figure 3. Variation of gas hydrate saturation with velocity at $70 \%$ porosity at fracture angles of $0^{\circ}$ and $90^{\circ}$.

In a borehole incidence angle, $0^{\circ}$ represents a horizontal fracture and an incidence angle of $90^{\circ}$ represents a vertical fracture. P-wave velocity was measured only at the study sites; therefore, gas hydrate saturation was estimated by assuming a fracture angle of $75^{\circ}$. An anisotropic study from the Krishna-Godavari basin shows a higher saturation compared to the isotropic modelling, assuming a horizontal fracture from the $\mathrm{P}$-wave velocity, and a quantum jump in saturation was estimated assuming a horizontal fracture from the S-wave velocity (Lee and Collett 2009; Wang et al. 2013). Figure 3 shows the nomogram of velocity versus hydrate saturations at $70 \%$ porosity, as porosity mainly varies within this range. Figures 4-6 from our study area show gas hydrate saturation estimates from the $\mathrm{P}$-wave velocity at three sites in the Mahanadi basin. We have also estimated gas hydrate saturations using Archie's equation from resistivity $\operatorname{logs}$ and compared with saturation obtained from isotropic and anisotropic modelling. The 

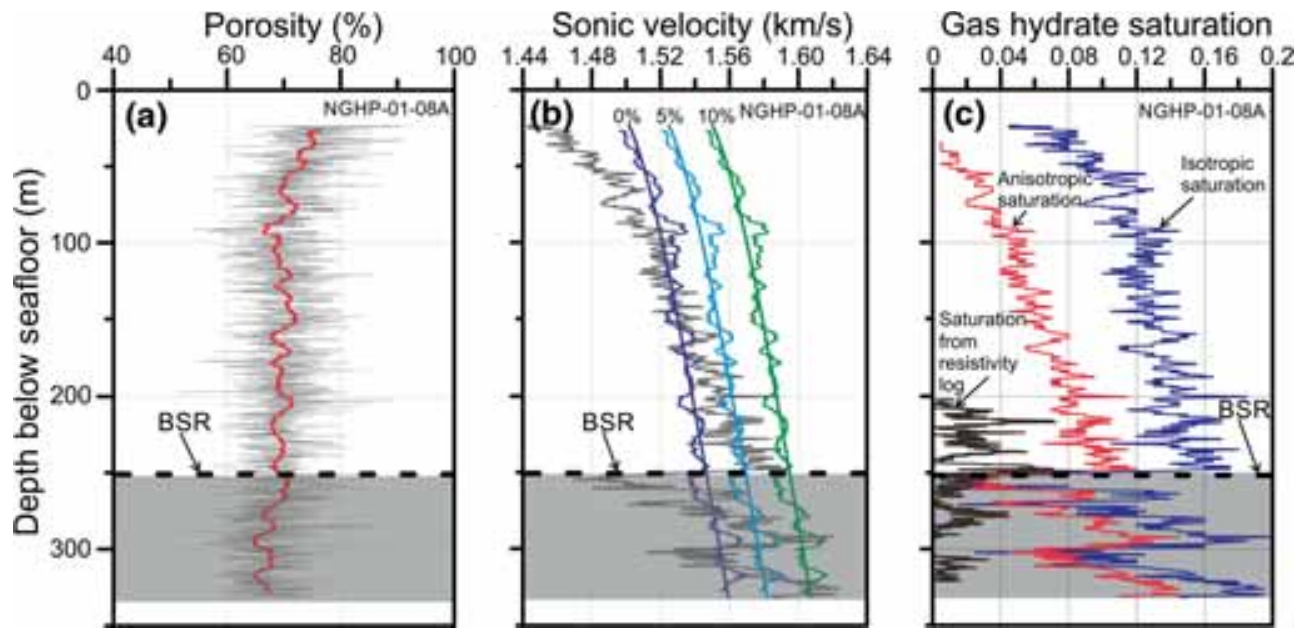

Figure 4. (a) Porosity versus depth LWD measurements at site NGHP-01-08A. The bold red curve shows the 3-m running average. (b) P-wave velocity measurements from sonic log and predicted velocities for gas-hydrate-bearing sediments using the gas hydrate in-frame rock physics model for varying gas hydrate saturation. Straight lines are based on linear porosity trends, whereas a 3-m running average was also used in the prediction to achieve a high resolution. (c) Gas hydrate saturation estimated from isotropic and anisotropic modelling.
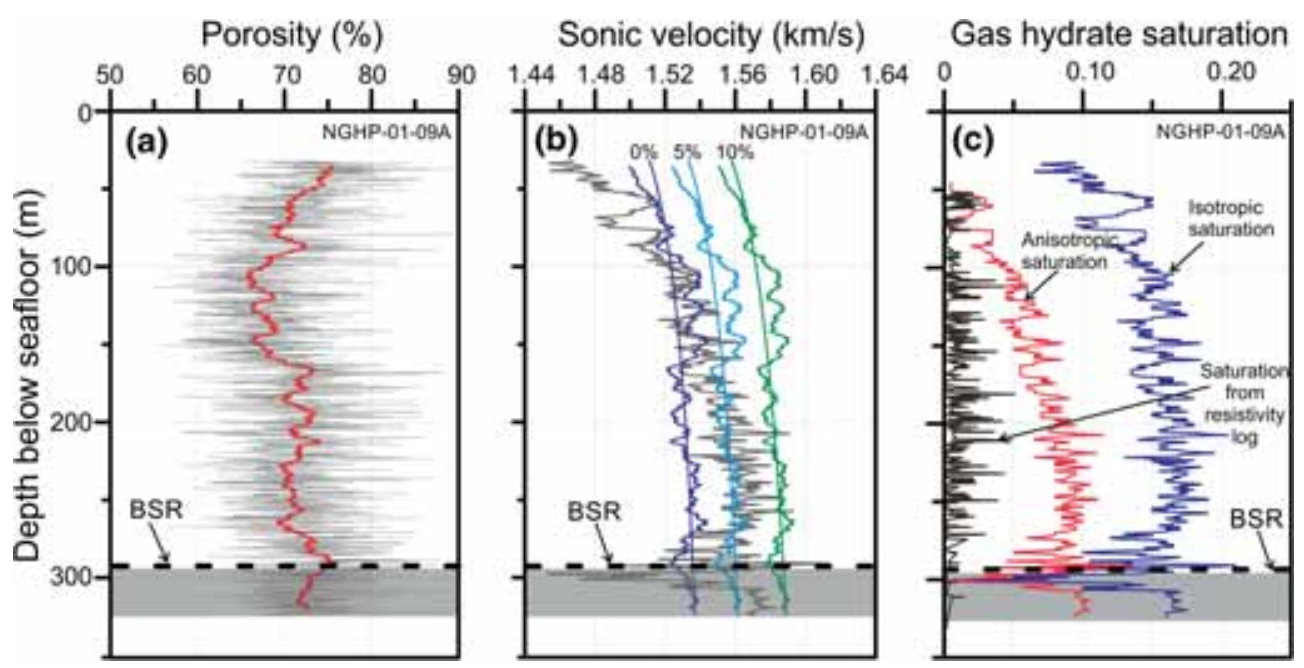

Figure 5. (a) Porosity versus depth LWD measurements at site NGHP-01-09A. The bold red curve shows the 3-m running average. (b) P-wave velocity measurements from sonic log and predicted velocities for gas-hydrate-bearing sediments using the gas hydrate in-frame rock physics model for varying gas hydrate saturation. Straight lines are based on linear porosity trends, whereas a 3-m running average was also used in the prediction to achieve high resolution. (c) Gas hydrate saturation estimated from isotropic and anisotropic modelling.

P-wave sonic velocity data at site NGHP-01-08 predicts gas hydrate saturation of a maximum of up to $10 \%$. However, the saturation obtained from the resistivity at this site shows less saturation compared to the velocity and shows close correspondence to the anisotropic saturation at the BSR depth. We observed that anisotropic modelling at this site shows $8-10 \%$ gas hydrate saturation which is half of the estimated saturation compared to isotropic modelling (figure $4 \mathrm{~b}$ and c). At site NGHP-01-09, isotropic modelling shows up to $18 \%$ hydrate saturation which is more than double the gas hydrate saturation compared to anisotropic modelling (figure 5c). In the high saturation area at site NGHP-01-19, starting from a depth of around 175 mbsf up to the BSR depth is more than 15\% (figure 6). However, isotropic and anisotropic models show similar gas hydrate saturation under $10 \%$ up to a depth of 175 mbsf. Below this depth to the BSR, the isotropic model shows a maximum of up to $20 \%$ gas hydrate saturation and the anisotropic model shows more than $10 \%$ gas hydrate saturation up to the BSR depth (figure 6). Figure 6(c) shows a comparison of gas hydrate 

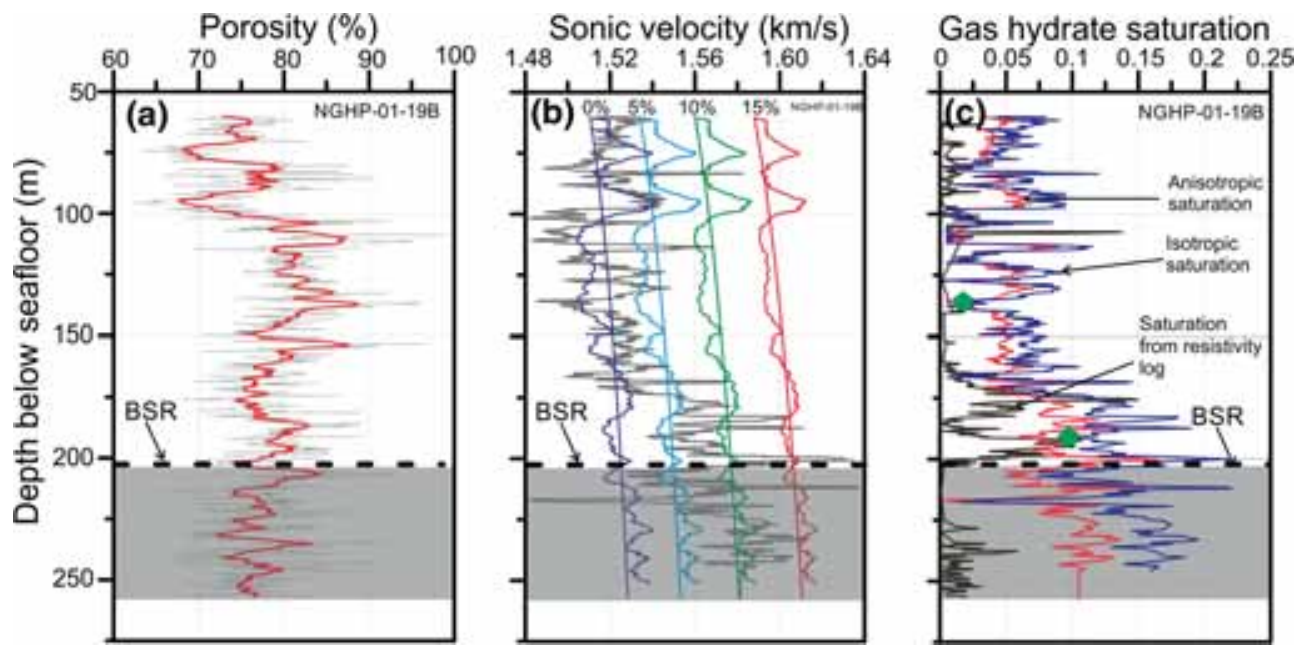

Figure 6. (a) Porosity versus depth wireline measurements at site NGHP-01-19B. The bold red curve shows the 3-m running average. (b) P-wave velocity measurements from sonic log and predicted velocities for gas-hydrate-bearing sediments using the gas hydrate in-frame rock physics model for varying gas hydrate saturation. Straight lines are based on linear porosity trends, whereas a 3-m running average was also used in the prediction to achieve high resolution. (c) Gas hydrate saturation estimated from isotropic and anisotropic modelling. The green diamond shape shows gas hydrate saturation measured from the pressure core.

saturations obtained from the velocity log and the resistivity log that match very well with the available pressure core values. We observed differences in saturation between isotropic and anisotropic at wells NGHP-01-8A and NGHP-01-9A, whereas at NGHP-01-19B, isotropic and anisotropic saturation are almost the same. Site NGHP-01-19B was drilled in complex structures and geometries typical of a channel cut-and-fill deposition of the Mahanadi basin. The 3D seismic data reveal a clear system of meandering distributary channels and early fan-type deposits (Shankar and Riedel 2014). However, sites NGHP-01-9A and NGHP01-8A were drilled in a clay-dominated sediment. The anisotropy effect can be observed more in a clay-dominated fine-grain sediment site compared to sand-dominated channel deposits.

\section{Conclusions}

We have used available logging data from the Indian NGHP Expedition-01 to estimate gas hydrate saturation at three sites (NGHP-01-08, -09, -19) in the Mahanadi basin. Gas hydrate saturations were estimated from $\mathrm{P}$-wave velocity using an effective medium isotropic and anisotropic modelling approach, defining average mineral assemblages based on sedimentological core descriptions. Saturation obtained from the isotropic model shows wide differences compared with the anisotropic model, providing results closer to the pressure core measurements. It is evident that in the presence of anisotropy, conventional models lead to an overestimation of gas hydrates. Therefore, anisotropy needs to be incorporated to obtain appropriate gas hydrate saturation estimates.

\section{Acknowledgements}

We would like to thank DGH and ONGC for their fruitful collaboration, especially by making the seismic and log data sets available for extended studies on the gas hydrate in the Mahanadi basin. We would like to thank the anonymous reviewer for the constructive review.

\section{References}

Bastia R, Radhakrishna M, Srinivas T, Nayak S, Nathaniel D $\mathrm{M}$ and Biswal T K 2010a Structural and tectonic interpretation of geophysical data along the Eastern Continental Margin of India with special reference to the deep water petroliferous basins; J. Asian Earth Sci. 39 608-619.

Bastia R, Radhakrishna M, Das S, Kale A S and Catuneanu O 2010b Delineation of the $85^{\circ} \mathrm{E}$ ridge and its structure in the Mahanadi Offshore Basin, Eastern Continental Margin of India (ECMI), from seismic reflection imaging; Mar. Petrol. Geol. 27 1841-1848.

Berryman J G and Milton G W 1991 Exact results for generalised Gassmann's equations in composite porous media with two constituents; Geophysics $\mathbf{5 6}$ 1950-1960

Bharali B, Rath S and Sarma R 1991 A brief review of Mahanadi delta and the deltaic sediments in Mahanadi 
basin; In: Quaternary deltas of India, Memoir, Vol. 22, GSI Publication, Bangalore, pp. 31-49

Carcione J M and Tinivella U 2000 Bottom-simulating reflectors: Seismic velocities and AVO effects; Geophysics $\mathbf{6 5}$ $54-67$.

Collett T S 2002 Energy resource potential of natural gas hydrates; Am. Assoc. Petrol. Geol. Bull. 86(11) 1971-1992.

Collett T S and Ladd J 2000 Detection of gas hydrate with downhole logs and assessment of gas hydrate concentrations (saturations) and gas volumes on the Blake ridge with electrical resistivity data; In: Proceedings of the Ocean Drilling Program, Scientific Results, Vol. 164, pp. 179-191.

Collett T S, Riedel M, Cochran J R, Boswell R, Presley J, Kumar P, Sathe A V, Sethi A, Lall M and Sibal V, NGHP Expedition 01 Scientists 2008 National gas hydrate program expedition 01; Initial Reports, Directorate General of Hydrocarbons, New Delhi.

Cook A E, Goldberg D and Kleinberg R L 2008 Fracturedcontrolled gas hydrate systems in the northern Gulf of Mexico; Mar. Petrol. Geol. https://doi.org/10.1016/j. marpetgo.2008.01.013

Dai J, Xu H B, Snyder F and Dutta N 2004 Detection and estimation of gas hydrates using rock physics and seismic inversion: Examples from the northern deep water Gulf of Mexico; Lead. Edge 23(1) 60-66.

Dai J, Snyder F, Gillespie D, Koesoemadinata A and Dutta N 2008 Exploration for gas hydrates in the deep water, northern Gulf of Mexico: Part I, a seismic approach based on geologic model, inversion, and rock physics principles; Mar. Petrol. Geol. 25 830-844.

Dangwal V, Sengupta S and Desai A G 2008 Speculated petroleum systems in deep offshore Mahanadi basin in Bay of Bengal, India; In: Proceeding of 7th international conference and exposition on petroleum geophysics, Hyderabad, India.

Dvorkin J and Nur A 1993 Rock physics for characterization of gas hydrates; In: The future of energy gases (ed) Howell D G, U.S. Geological Survey Professional Paper, Vol. 1570 , pp. 293-311.

Dvorkin J and Nur A 1996 Elasticity of high-porosity sandstones: Theory for two North Sea data sets; Geophysics 61 1363-1370.

Dvorkin J and Nur A 1998 Acoustic signatures of patchy saturation; Int. J. Solids Struct. 35 4803-4810.

Dvorkin J, Prasad M, Sakai A and Lavoie D 1999 Elasticity of marine sediments: Rock physics modeling; Geophys. Res. Lett. 26(12). https://doi.org/10.1029/ 1999GL900332.

Dvorkin J, Nur A, Uden R and Taner T 2003 Rock physics of a gas hydrate reservoirs; Lead. Edge $\mathbf{2 2}$ 842-846.

Ecker C, Dvorkin J and Nur A 1998 Sediments with gas hydrate: Internal structure from seismic AVO; Geophysics 63 1659-1669.

Ecker C, Dvorkin J and Nur A 2000 Estimating the amount of gas hydrate and free gas from marine seismic data; Geophysics 65 565-573.

Fuloria R C, Pandey R N, Bharali B R and Mishra J K 1992 Stratigraphy, structure and tectonics of Mahanadi offshore basin; In: Recent Geoscientific Studies in the Bay of Bengal and the Andaman Sea; J. Geol. Soci. India Spec. Publ. 29 255-265.

Gassmann F 1951 On the elasticity of porous media; Vierteljahr. Naturforsch. Ges. Zurich 96 1-23.

Ghosh R, Sain K and Ojha M 2010 Effective medium modeling of gas hydrate-filled fractures using sonic log in the Krishna-Godavari basin, eastern Indian offshore; J. Geophys. Res. 115 B06101. https://doi.org/10.1029/ 2009JB006711.

Gibson R L Jr and Toksoz M N 1990 Permeability estimation from velocity anisotropy in fractured rocks; J. Geophys. Res. 95 15643-15656.

Guerin G, Goldberg D and Melsterl A 1999 Characterization of in situ elastic properties of gas hydrate-bearing sediments on the Blake Ridge; J. Geophys. Res. 104 17781-17796.

Helgerud M B 2001 Waves speeds in gas hydrate and sediments containing gas hydrate: A laboratory and modeling study; PhD Dissertation, Stanford University, 249.

Helgerud M B, Dvorkin J and Nur A 1999 Elastic-wave velocity in marine sediments with gas hydrates: Effective medium modeling; Geophys. Res. Lett. 26 2021-2024.

Holland M, Schultheiss P, Roberts J and Druce M 2008 Observed gas hydrate morphologies marine sediments; In: Proceedings of the 6th International Conference on Gas Hydrates, Vancouver, BC, Canada, pp. 6-10.

Hyndman R D, Yuan T and Moran K 1999 The concentration of deep sea gas hydrates from downhole electrical resistivity logs and laboratory data; Earth Planet. Sci. Lett. 172 167-177.

Hyndman R D, Spence G D, Chapman N R, Riedel M and Edwards R N 2001 Geophysical studies of marine gas hydrate in northern Cascadia; In: Natural Gas Hydrates: Occurrence, Distribution, Detection (eds) Paull C K and Dillon W P, Am. Geophys. Union Monogr. 124 273-295.

Jakobsen M, Hudson J A, Minshull T A and Singh S C 2000 Elastic properties of hydrate-bearing sediments using effective medium theory; J. Geophys. Res. 105(B1) 561-577.

Kastner M, Claypool G and Robertson G 2008 Geochemical constraints on the origin of the pore fluids and gas hydrate distribution at Atwater Valley and Keathley Canyon, northern Gulf of Mexico; Mar. Petrol. Geol. 25 860-872.

Kuster G T and Toksöz M N 1974 Velocity and attenuation of seismic waves in two phase media: Part I. Theoretical formulations; Geophysics 39 587-606.

Lee M W and Collett T S 2005 Assessments of gas hydrate concentrations estimated from sonic logs in the JAPEX/JNOC/GSC et al. Mallik 5L-38 gas hydrate research production well; In: Scientific results from the Mallik 2002 Gas Hydrate Production Research Well Program, Makenzie delta, Northwest Territories, Canada (eds) Dallimore S R and Collett T S, Bull. Geol. Surv. Can. 58510.

Lee M W and Waite W F 2008 Estimating pore-space gas hydrate saturations from well log acoustic data; Geochem. Geophys. Geosyst. 9 Q07008. https://doi.org/10.1029/ 2008GC002081.

Lee M W and Collett T S 2009 Gas hydrate saturations estimated from fractured reservoir at site NGHP-01-10, Krishna-Godavari basin, India; J. Geophys. Res. 114 B07102. https://doi.org/10.1029/2008JB006237. 
Lee M W, Hutchinson D R, Dillon W P, Miller J J, Agena W F and Swift B A 1993 Method of estimating the amount of in situ gas hydrates in deep marine sediments; J. Mar. Petrol. Geol. 10 496-506.

Mathur M C, Sinharay S, Ravindranath R and Sharma M 2008 Identification of sandy marine gas hydrates and deep water depositional elements in gas hydrate stability zones; In: Extended Abstract Presented in 7th Biennial International Conference and Exposition on Petroleum Geophysics, Hyderabad, India, 408p.

Mavko G and Jizba D 1991 Estimating grain-scale fluid effects on velocity dispersion in rocks; Geophysics $\mathbf{5 6}$ 1940-1949.

Mavko G, Chan C and Mukerji T 1995 Fluid substitution: Estimating changes in $V_{\mathrm{p}}$ without knowing $V_{\mathrm{s}}$; Geophysics 60 1750-1755.

Mohapatra P 2006 Sequence stratigraphic approach for identification of hydrocarbon plays in Mahanadi offshore basin; In: Proceeding of 6th International Conference and Exposition on Petroleum Geophysics, Kolkata, India.

Nur A 1971 Effect of stress on velocity anisotropy in rocks with cracks; J. Geophys. Res. 76 2022-2034.

Ojha M and Sain K 2013 Quantification of gas hydrates and free gas in the Andaman offshore from downhole data; Curr. Sci. 105 512-516.

Prakash A, Samanta B G and Singh N P 2010 A seismic study to investigate the prospect of gas hydrate in Mahanadi deep water basin, northeastern continental margin of India; Mar. Geophys. Res. 31 253-262.

Ramana M V, Ramprasad T, Paropkari A L, Borole D V, Ramalingeswara B R, Karisiddaiah S M, Desa M, Kocherla M, Joao H M, Loka-bharathi P, Gonsalves M-J, Pattan J N, Khadge N H, PrakashBabu C, Sathe A V, Kumar P and Sethi A K 2009 Multidisciplinary investigations exploring indicators of gas hydrates occurrence in the Krishna-Godavari basin offshore, east coast of India; Geo-Mar. Lett. 29 25-38.

Sain K, Ojha M, Satyavani N, Ramadass G A, Ramprasad T, Das S K and Gupta H K 2012 Gas hydrates in KrishnaGodavari and Mahanadi basins: New data; J. Geol. Soc. India $79553-556$.
Satyavani N, Alekhya G and Sain K 2015 Free gas/gas hydrate inference in Krishna-Godavari basin using seismic and well log data; J. Nat. Gas Sci. Eng. 25 317-324.

Shankar U and Riedel M 2011 Gas hydrate saturation in the Krishna-Godavari basin from P-wave velocity and electrical resistivity logs; Mar. Petrol. Geol. 28 1768-1778.

Shankar U and Riedel M 2014 Assessment of gas hydrate saturation in marine sediments from resistivity and compressional-wave velocity log measurements in the Mahanadi basin, India; Mar. Petrol. Geol. 58 265-277.

Shankar U, Gupta D K, Bhowmick D and Sain K 2013 Gas hydrate and free-gas saturations using rock physics modelling at site NGHP-01-05 in the Krishna-Godavari basin, eastern Indian margin; J. Petrol. Sci. Eng. 106 $62-70$.

Subrahmanyam V, Subrahmanyam A S, Murty G P S and Murthy K S R 2008 Morphology and tectonics of Mahanadi basin, northeastern continental margin of India from geophysical studies; Mar. Geol. 253 63-72.

Subramanian V 1978 Input by Indian rivers into the world oceans; Proc. Indian Acad. Sci. A: Earth Planet. Sci. 87 77-88.

Wang X, Sain K, Satyavani N, Wang J, Ojha M and Wu S 2013 Gas hydrate saturation using geostatistical inversion in a fracture reservoir in the Krishna Godavari basin, offshore eastern India; Mar. Petrol. Geol. 45 224-235.

White J E 1965 Seismic waves-radiation, transmission, and attenuation; McGraw-Hill, New York, 302p.

Xu H, Dai J, Snyder F and Dutta N 2004 Seismic detection and quantification of gas hydrates using rock physics and inversion; In: Advances in Gas Hydrates Research (eds) Taylor C E and Kwan J T, Kluwer, New York, pp. 117-139.

Yuan T, Hyndman R D, Spence G D and Desmons B 1996 Seismic velocity increase and deep-sea gas hydrate above a bottom-simulating reflector on the northern Cascadia continental slope; J. Geophys. Res. 101 13655-13671. 